Universidad de Lima

Facultad de Comunicación

Carrera de Comunicación

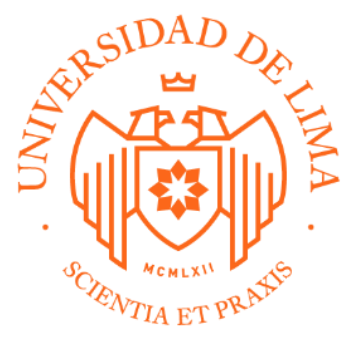

\title{
Mano y madera
}

Trabajo de Suficiencia Profesional para optar el Título Profesional de Licenciado en Comunicación

\section{Luisa Fernanda Bravo Tenorio \\ Código 20120206}

\section{Jessica Elizabeth Velazco Lopez \\ Código 20122302}

\author{
Lima - Perú
}

[Septiembre 2019] 
Mano y madera 


\section{ÍNDICE}

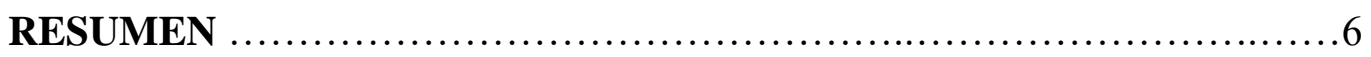

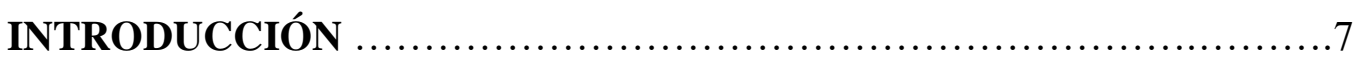

1. ANTECEDENTES DEL TRABAJO $\ldots \ldots \ldots \ldots \ldots \ldots \ldots \ldots \ldots \ldots \ldots \ldots \ldots$

1.1 Nociones básicas....................................................... 8

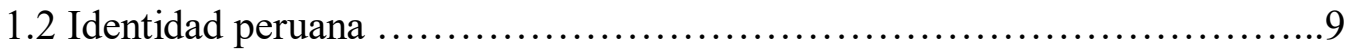

1.3 Música tradicional de la costa peruana ...............................10

1.4 Historia del cajón y percusión.......................................11

1.5 Multiculturalidad ............................................... 13

1.6 Concientización e identidad.............................................. 14

1.7 Referencias De Documentales Visionados................................14

1.7.1 Documental Cholet

1.7.2 El viaje del cajón de Perú a Madrid

2. PROPUESTA DE COMUNICACIÓN ..................................... 16

2.1 Estrategias ....................................................... 16

2.1.1 Objetivo ....................................................... 16

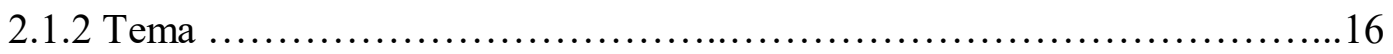

2.1.3 Sinopsis .......................................................16

2.1.4 Argumento ......................................................16

2.1.5 Elección de personajes ..............................................16

2.1.6 Preguntas para los entrevistados ...................................17

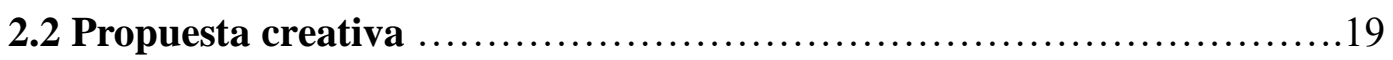

2.2.1 Casting de espacios .............................................20

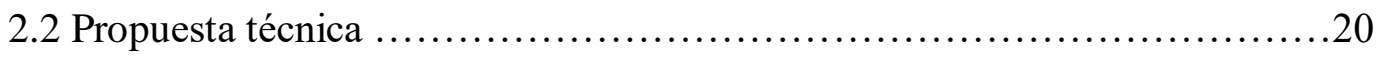

2.2.1 Plan de rodaje

2.2.2 Plan de producción de necesidades y gastos

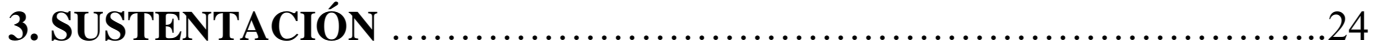

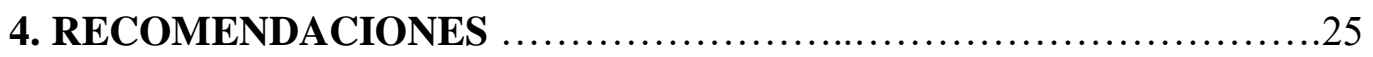

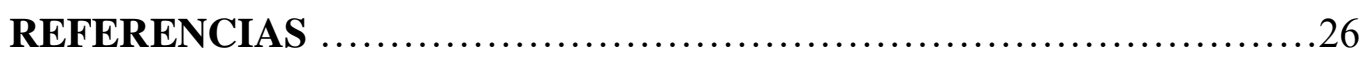

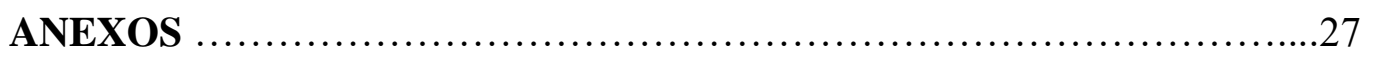


Dirección web de las piezas y producciones de comunicación parte del trabajo

https://www.youtube.com/watch?v=6T7jFHOIHqM\&feature=youtu.be 


\section{RESUMEN EN ESPAÑNOL}

Este documental es sobre el cajón peruano como símbolo de identidad peruana. Abordaremos el tema por medio de conversaciones con músicos cajonistas, expertos en percusión y un sociólogo, que nos darán a conocer el valor y la carga de identidad que lleva dicho instrumento. Asimismo, trataremos de abordar cómo se ha transformado en uno de los instrumentos bandera, fundamentalmente para la música criolla, afroperuana e internacional y cómo ello ha sido motivo de orgullo para los peruanos.

\section{Palabras clave: Cajón, Música, Identidad, Peruano, Cultura}

\section{RESUMEN EN INGLÉS}

This documentary is about the 'cajón peruano' as a symbol of peruvian identity. We will explain the topic through personal conversations with musicians and percussion experts that will make us aware of the value and identity load that this instrument carries. Also, we will try to present briefly, how it has become one of the flagship instruments, mainly for "música criolla", Afro-Peruvian and even international music and how it has been a source of pride for peruvians.

Keywords: Cajón, Music, Peruvian, Identity, Culture 


\section{INTRODUCCIÓN}

El presente trabajo de análisis documental demuestra la importancia y el aporte de los instrumentos y diversos ritmos de los peruanos como parte de nuestra identidad, en esta ocasión ahondaremos en el cajón peruano, como aporte a la construcción y formación de la identidad nacional de las generaciones actuales y las nuevas. Tomar el patrimonio cultural y revalorizarlo como parte de la identidad de la nación, saber la historia de nuestro pasado en el presente para preservarlo tomando en cuenta que nos encontramos rumbo al Bicentenario de la Independencia del Perú.

En este documental trataremos de explicar cómo el cajón enriqueció, de cierto manera, a la sociedad, a la música criolla y por ende a los demás ritmos peruanos, como la marinera, el folklore, el vals, entre otros. Además surgieron muchas dudas al respecto como ¿Qué aportó el cajón para la historia de nuestro país? ¿Cómo se internacionalizó al punto de ser un instrumento de percusión reconocido mundialmente? ¿Por qué el peruano se identifica tanto con el cajón? Trataremos de abordar estas y otras preguntas en este documental.

Tomamos este espacio audiovisual para hacer reflexión sobre la importancia de elementos importantes que forman parte de nuestra identidad como es el cajón peruano. A vísperas de la celebración de la llegada del Bicentenario, como peruanos debemos recordar los lazos entre nuestros habitantes y todos aquellos símbolos históricos y culturales que de alguna manera ayudan a conservar nuestro patrimonio cultural y concientizar a las nuevas generaciones y al mundo sobre el tema. 


\section{ANTECEDENTES DEL TRABAJO}

\subsection{NOCIONES BÁSICAS}

Para iniciar la investigación y tener una mejor comprensión del trabajo, comenzaremos definiendo los conceptos claves:

a. Identidad. "El concepto de identidad cultural encierra un sentido de pertenencia a un grupo social con el cual se comparten rasgos culturales, como costumbres, valores y creencias. La identidad no es un concepto fijo, sino que se recrea individual y colectivamente y se alimenta de forma continua de la influencia exterior." (Molano, O.,s.f,p.73)

b. Identidad nacional. "La identidad es un sentimiento, cuyos componentes emocionales deben ser sólo un motivador de un constructo mucho más complejo: Una convicción de pertenencia, de origen y destino comunes, de identificación entre diversos, de respeto entre personas y adicionalmente de respeto a los procesos sociales y valores." (Milla Vidal, C., 2003, p.7)

c. Esencia. "Aquello que constituye la naturaleza de las cosas, lo permanente e invariable de ellas”. Real Academia Española. (2014). Diccionario de la lengua española $\left(23\right.$. $^{\mathrm{a}}$ ed.).

d. Idiosincrasia. "Rasgos, temperamento, carácter y distintivos propios de un individuo o colectivo". Real Academia Española. (2014). Diccionario de la lengua española (23. ${ }^{a}$ ed.).

e. Multiculturalidad. "La multiculturalidad se puede definir como la presencia en un territorio de diferentes culturas que se limitan a coexistir pero no a convivir; es entendida como la existencia de diferentes grupos culturales en un mismo territorio.” (Bernabé Villodre,M.,2012 ,p.69)

\subsection{IDENTIDAD PERUANA}


La identidad peruana es muy compleja y ha sido construida por inevitables fusiones que derivan a lo que somos hoy, una sociedad llena de complejidad, tenemos valores y un espíritu distintivo, rico y diverso. El Perú es un país megadiverso con distintos elementos, incluyendo los idiomas nativos, la música y la danza que nos hacen temblar hasta los huesos y siempre han tenido un papel importante en nuestra sociedad, la comida, la riqueza histórica y cultural, al igual que muchas otras riquezas que nos consolidan como un país acogedor y con múltiples colectivos que hoy en día reconocemos como parte de nuestra cultura.

Mucha gente cree que la identidad se construye mediante grandes batallas o actos heroicos, sin embargo, la identidad se construye muchas veces sobre cuestiones del día a día, que nos hacen sentir orgullosos. A diferencia de muchos otros países que conservan pocos elementos como tradicionales o como parte de la cultura, nosotros tenemos bastante de qué estar orgullosos, y esto va desde la gastronomía hasta la música e inclusive formas de comportamiento que nos hacen peruanos.

Actualmente se dice que nos falta identidad nacional, sin embargo, sabemos que no hay ser humano ni colectividad nacional sin rasgos propios u originales. Según nos comentó el sociólogo Javier Díaz-Albertini, especialista en temas urbanos, la identidad nacional es lo que permite que un conjunto de personas puedan actuar como un colectivo, es una comunidad imaginaria como dicen los expertos. Al igual que te imaginas un vecindario, te imaginas un país, pero para imaginarte ese país tienes que tener cuestiones que te hagan sentir parte de él. Cuestiones como por ejemplo, el deporte, la gastronomía, nuestro himno, Machu picchu, entre otros elementos que de todas maneras hacen que la gente piense "'esto es parte de mi país, esta es mi identidad".

Es ahí donde nos encontramos con elementos de identidad como el cajón. El cajón instrumento y símbolo que mientras el país se va volviendo más urbano, más global, este va adquiriendo mayor presencia en diferentes estilos de música en Perú. Es un instrumento netamente nacional, antes estaba más ligado a la música criolla nada más pero hoy empieza a tener un carácter más nacional.

El cajón es tan versátil en todos los aspectos, siendo un instrumento que puede ser considerado sencillo, se convierte muchas veces en objeto de alegría para el peruano, en 
algo que la gente lleva a partidos, a fiestas, al extranjero como recuerdo, a animar algún espacio, etc.

\subsection{MÚSICA TRADICIONAL DE LA COSTA PERUANA}

La música peruana desde su desarrollo ha sido influida por múltiples procesos socio históricos, desde fenómenos migratorios internos hasta migraciones de países geográficamente lejanos del Perú de los cuales recibimos influencia de vertientes culturales europeas, africanas e indígenas.

Si vemos la música tradicional de la costa desde un punto de vista étnico y cultural, nuestra población es, en gran parte, mestiza; siendo el resultado biológico y cultural de las distintas etnias que llegaron desde la Colonia hasta la actualidad. Es por eso que consideramos tanto al país como la música, multicultural.

Dentro de la música de la costa encontramos la música criolla, uno de los géneros más asociados a esta es el vals. El vals se empezó a desarrollar a fines del siglo XIX y a principios del XX. Automáticamente al pensar en música criolla se nos viene a la mente el sonido del cajón acompañando a los intérpretes. La majestuosidad del sonido del cajón para el vals es indispensable.

El vals empieza a ser más aceptado entre los sectores de clase media y media alta como un símbolo del «ser limeño» y, por extensión, costeño y peruano. Esto produce muchos cambios en la práctica popular musical, sobre todo en relación a la expansión del vals en los medios de comunicación, la profesionalización del músico popular y la institucionalización y transformación de la jarana de barrio en actividades vinculadas a centros musicales y, luego, peñas y establecimientos comerciales. (León, 2010, p.200)

Por otro lado, en la música afroperuana también encontramos un carácter híbrido ya que combinaba elementos e influencias con elementos musicales africanos, europeos y también andinos. A pesar de que hubo un tiempo en el cual este tipo de música desapareciera debido a la presión que existía de parte de la cultura criolla que era la más dominante, sobrevivió en el tiempo y fue popularizada gracias a grandes músicos como Nicomedes Santa Cruz y Victoria Santa Cruz que contribuyeron a que esta mezcla híbrida fuera recibida con mayor entusiasmo por el público peruano. 
En los últimos años, se ha renovado el interés por los géneros afroperuanos, en gran parte impulsado por el «descubrimiento» a mediados de los años 90 de la cantante Susana Baca por parte del circuito internacional de la world music y por la colaboración de músicos afroperuanos con artistas de otras vertientes musicales, con el fin de desarrollar nuevos estilos de jazz, música electrónica, rock y salsa pero con carácter peruano. (León. 2010, p. 203)

Con la música criolla y afroperuana traspasando fronteras dentro de las distintas variantes de música dentro del Perú y el extranjero, el cajón peruano se consolidó en el ámbito nacional en la segunda mitad del siglo XX. convirtiéndose en un instrumento que se originó desde lo más bajo, en sectores populares y zonas esclavas y marginales, hasta posicionarse como importante e indispensable para la música peruana en general.

\subsection{HISTORIA DEL CAJÓN Y PERCUSIÓN}

Actualmente podemos sentirnos contentos de considerar al cajón como elemento de orgullo y representación nacional. Este instrumento de madera no solo se utiliza para acompañar diversos ritmos de la música peruana, sino también como una especie de elemento recordatorio de nuestra cultura, es un instrumento bandera y es el instrumento peruano más internacional que poseemos debido a su historia y todas las variaciones por las que ha pasado.

El cajón tiene su origen en la zona de Chincha, al sur de Lima, región donde hay una gran población de origen africana. Este instrumento creado en la costa central de nuestro país fue desarrollado por esclavos africanos durante los últimos años de la era colonial. Comenzaron a utilizarse los cajones de embalaje en desuso, cajones de frutas y otros materiales de madera como instrumentos alternativos a los tradicionales tambores, ya que habían sido prohibidos por los españoles. Nadie imaginaría que tiempo después el cajón peruano conquistaría el mundo.

Hacia principios del S. XVII se hizo pública una prohibición de la Iglesia Católica para el uso de los tambores que utilizaban los esclavos, al considerarlos paganos y así evitar la comunicación a distancia. Existía miedo por parte de las instituciones de la época, de que este instrumento sirviera para que entre ellos se 
comunicaran y pudieran de alguna manera suponer un peligro para las intenciones de la corona. (Guerrero García, 2014, p. 2)

Algunos autores afirman que el cajón data de 1,900 y otros aseguran que este instrumento ya existía en el año de 1,850. Según el autor José Antonio del Busto, el cajón reemplazó los tambores de pie que trajeron africanos al ser prohibidos por los españoles. Carlos Castro, investigador argentino, señala que los africanos en el Perú durante los siglos XVIII y XIX, especialmente en la Costa del Pacífico, que para las fiestas se usaba de tambor los cajones de fruta y de otros alimentos que se encontraban en desuso en los puertos. Estos pueden considerarse los antecesores a nuestro cajón.

Al igual que en la percusión, los ritmos peruanos de marcada influencia española han ido transformándose, adoptando más elementos criollos y negros, y van tomando diferentes nombres, el Landó o Tondero, el Panalivio, el Aguenieves, el Payandé y el Festejo, para luego dar origen a la zamacueca, que queda oficializada como baile nacional con el nombre de Marinera, en honor a la flota naval Peruana. Estos ritmos cobraron forma con la inclusión del cajón, que se convierte, casi exclusivo y auténticamente en el instrumento peruano de percusión, por excelencia. (Guerrero García, 2014, p. 3)

A pesar de saberse todo esto, han habido dudas sobre el verdadero origen del cajón debido a su internacionalización, se supuso que el cajón era de origen ibérico, debido a su uso en ritmos flamencos. La aclaración llega gracias a Rafael Santa Cruz, quien dedicó años de su vida para lograr el reconocimiento del instrumento peruano, dándole el valor que merecía.

Hoy en día, el 02 de agosto ha sido declarado por el Ministerio de Cultura el Día del Cajón Peruano, conmemorando al popular instrumento nacional, considerado Patrimonio Cultural de la Nación. Un día para rendir homenaje a este instrumento considerado Patrimonio Cultural de la Nación desde el 2001. Ley N 30716.

\subsection{MULTICULTURALIDAD}

¿Qué es la multiculturalidad? Como concepto sociológico, el autor Miguel Argibay (2003) nos dice que la multiculturalidad significa la existencia de diferentes culturas en un mismo espacio geográfico y social. Esta mezcla de culturas y tradiciones en el caso 
de nuestro país, Perú, se han ido dando a través del tiempo gracias a la migración interna así como a la inmigración de pobladores de otros continentes, como Europa, Asia, África y Norteamérica.

El conjunto de tradiciones y costumbres adoptados por los peruanos se convirtieron en rasgos significativos que se siguen modificando de generación en generación y forman parte de nuestra identidad. En el caso de la música de la costa peruana, se recibió gran parte de influencia Española durante la colonia y se estableció durante la República dando espacio a lo que conocemos como la música criolla. Por otro lado, la música también se vio influenciada por la llegada de los esclavos negros de África, de quienes heredamos los ritmos del tondero y del festejo.

Es importante resaltar que la llegada de las poblaciones afroperuanas hasta el siglo XIX, fueron poderosa influencia en cuanto a la percusión, variedad de instrumentos fueron apareciendo, realizados incluso con troncos de árboles, calabazas, cajas de madera de frutas, etc. Entre estos, el cajón peruano, llamado por Nicomedes Santa Cruz como "Su Majestad el Cajón” nació como instrumento en sí de esta unión de diversidad que se estaba dando a comienzos del siglo XVI.

Los ritmos que empleaban el cajón como instrumento tenían marcada la influencia española pero se fueron transformando y adaptando lo criollo y negro, así van tomando distintos nombres como la zamacueca, el tondero, etc. El cajón entonces surgió como instrumento casi exclusivamente peruano y hoy es un símbolo de nuestra identidad, que puede ser incorporado a cualquier otro ritmo nacional e internacional para aportar sabor y riqueza con su sonido y ritmo.

\subsection{CONCIENTIZACIÓN E IDENTIDAD}

En el escenario en el que vivimos actualmente, la relación entre el patrimonio cultural y la educación sobre cada parte de la historia del Perú deberían ser prioridad dentro de la plana educativa. El despertar el interés por el pasado, pontencia nuestra conciencia sobre los orígenes e incluso nuestra identidad peruana.

Ayudar a los alumnos en la comprensión de sus propias raíces culturales y de la herencia común. Este aspecto va íntimamente ligado al punto anterior. No se puede imponer una cultura estándar ni uniforme en el ámbito planetario a los 
jóvenes de una sociedad tan diversa culturalmente como la actual. Sin embargo, es bien cierto que compartimos una gran parte de la cultura común. Es necesario colocar esta "herencia" en su justo contexto. (Martínez Valcárcel, N. s.f, p.9)

La compresión de nuestras raíces no sólo va dirigido hacia temas de historia universal y peruana por el lado político y gubernamental, es importante también promover y concientizar que la música peruana, como tal, no es solo música, sino una forma distinta de mostrar características de la identidad cultural peruana. Tal como destaca el autor Hood Mantle (1957), no podemos olvidar que la función de la música es relevante como un aspecto de la conducta del hombre en la sociedad, incluso él considera que el valor intrínseco de la música suma como un aporte social. En suma, Hood Mantle (1957) destaca la importancia de la "función social, estilo musical y valor musical" (p.2-8).

\subsection{REFERENCIAS DE DOCUMENTALES VISIONADOS}

\subsubsection{Documental Cholet}

Año: 2015

Dirigida por Isaac Niemand

Documental presentado en el Festival de Cine de Arquitectura de Rotterdam que muestra el trabajo arquitectónico del boliviano Freddy Mamani en El Alto, Bolivia, con construcciones representativas de la nueva burguesía aymara, con la que el protagonista contribuye al surgimiento de la neo arquitectura andina. Nos permite observar el contraste que generan las obras de este ingeniero en una clase social que se empodera desde elementos propios de su cultura. Este documental nos sirvió como ejemplo, pues se muestra el orgullo de este innovador por la cultura andina para el mundo. Por otro lado, existe un gran apoyo con videos y fotografías de archivo para respaldar los conflictos sociales tocados en el documental

\subsubsection{El viaje del cajón de Lima a Madrid}


Año: 2011

Directores: Javier Calvo

Documental testimonial para el programa de TVE2 Entre2aguas, nos presenta diversos personajes que nos relatan el origen del cajón, cómo ha ido evolucionando a través del tiempo en los diversos ritmos y cómo fue que llegó hasta Madrid para revolucionar al flamenco. Este documental nos sirvió para aterrizar la organización de nuestro proyecto. También consideramos las entrevistas a los personajes, pues trabajamos con testimonios similares. 


\section{PROPUESTA DE COMUNICACIÓN}

\subsection{ESTRATEGIAS:}

\subsubsection{Objetivo}

Promover la identidad peruana a través del cajón.

\subsubsection{Tema}

El cajón peruano como símbolo de la identidad nacional

\subsubsection{Sinopsis}

Tres músicos peruanos, percusionistas y profesores de música, nos contarán su historia y trayectoria a través de ella, la forma en la que la música enriqueció su identidad y formación como artistas y peruanos. Además, un sociólogo ahondará en cómo se construye la identidad peruana a través de símbolos, como el cajón.

\subsubsection{Argumento}

Este documental se basará en el testimonio de tres cajonistas, quienes nos contarán sobre la historia de este instrumento de percusión, qué papel cumplió en sus vidas y cómo la música, sobretodo el cajón, los identifica como peruanos. Un músico y fabricante de cajones nos brindará todos sus conocimientos sobre el proceso de "hacer" un cajón y podremos observar algunos aspectos de ello en el taller de la marca A Tempo. Cada uno de ellos, a su manera, trata de difundir la música peruana como parte de nuestra cultura e identidad. Finalmente, un sociólogo nos explicará el valor de la identidad nacional en una sociedad y cómo el cajón peruano es un símbolo de la nuestra.

\subsubsection{Elección de personajes:}

1. Juan Manuel Serra Carlín: Músico percusionista, cajonero de flamenco y música criolla. Profesor de música y educación secundaria. Actualmente se encuentra en formación en lengua y literatura. Forma parte de la Escuela de Flamenco Alma Gitana - Perú, su madre es gestora y dueña de la escuela. 
2. Francisco Vilela: Músico percusionista aún en formación en la UPC y profesor de cajón independiente. Creador de Kilombo, organización cultural ganadora de el premio: Lima Verde Parques \& Jardines Innovación, está conformada por gestores culturales y artistas especializados en diferentes disciplinas como son la música, el circo, el teatro, la danza y las artes visuales. Francisco se dedica a la música y a actividades que promueven el desarrollo de los niños en ella.

3. Alexis Castañeda: economista, luthier y músico Peruano. Actualmente se encuentra dedicado a su empresa y marca A tempo percusión, es uno de los más grandes fabricantes de cajones del Perú y el que más vende a marcas del extranjero. Los cajones que fabrica Alexis son tocados por casi todos los grandes percusionistas del país y músicos peruanos.

4. Ricardo Huapaya: Músico y profesor de cajón peruano, dedicado a su música desde muy pequeño, actualmente se encuentra laborando en el rubro del entretenimiento en la Peña del Carajo, brindando shows musicales y bailables los fines de semana con su agrupación.

5. Javier Díaz-Albertini: Sociólogo, especialista en temas urbanos, ONGS y la cooperación internacional. Actualmente es profesor e investigador de la Universidad de Lima. Autor del libro "Redes cercanas: El capital social en Lima".

\subsubsection{Preguntas para los entrevistados:}

\section{Entrevista para los cajoneros:}

1. ¿Qué es para ti el cajón peruano?

2. ¿Cómo aprendiste y cuál fue el papel del cajón en tu vida?

3. ¿Qué puedes contarnos sobre la historia o qué conocimientos tienes sobre los inicios de este instrumento?

4. ¿Cómo el cajón enriqueció a la música criolla y la música de la costa? ¿De qué manera consideras que el ingreso de otros instrumentos y ritmos “caribeños" han transformado el folklore/música peruana? 
5. ¿Qué opinas sobre el reconocimiento del cajón peruano como patrimonio cultural?

6. ¿Qué opinión tienes sobre la siguiente frase? : 'La música ha servido para que muchos pueblos soportan la esclavitud y la opresión."

7. ¿Crees que la música históricamente deja huellas de acontecimientos de la vida misma/en el país?(refiriéndose a que constituye un paisaje sonoro y material)

8. ¿Cómo crees que ha evolucionado el valor del trabajo musical a través de los años?

9. ¿Crees que la música sirve como una expresión de alma?

10. ¿Qué quieres que la gente sienta cuando te escucha tocar? ¿Cómo llegas a ellos?

11. ¿Qué es lo que hace que el peruano le ponga tanta pasión, creatividad y amor a la música?

12. ¿Crees que la música sirve de expresión para mostrar lo que es nuestro país?

\section{Entrevista para el sociólogo:}

1. ¿Cuál es el valor de la identidad nacional en una sociedad?

2. ¿Qué ha ayudado a que la identidad en nuestro país crezca en los últimos años?

3. ¿Qué obstáculos y oportunidades encuentra en su identidad un país como el nuestro?

4. El cajón es un referente de nuestra cultura, ¿Se considera como un símbolo del imaginario popular?

5. ¿Qué carácter tiene el cajón como instrumento en nuestra cultura? 
6. Los peruanos estamos cada vez más orgullosos de la riqueza histórica y cultural del pasado y presente, ¿La música es un factor importante para aumentar este "orgullo peruano"?

7. ¿Considera que como símbolo, el cajón peruano, tiene algo de nuestro ADN en sí?

\subsection{PROPUESTA CREATIVA}

\subsubsection{Casting de espacios}

Todas las grabaciones fueron realizadas con iluminación en clave alta en los espacios proporcionados por nuestros personajes con el fin de que se sintieran en un espacio cómodo para ellos y sobretodo en lugares donde comparten su arte. En el caso de Juan Manuel Serra, se realizó en la escuela de flamenco de su familia, en la cual vivió por mucho tiempo y en la que actualmente se encuentra dando clases de percusión y cajón. En el caso de Francisco Vilela, nos brindó la facilidad de realizar la grabación en su hogar, situado en Villa el Salvador, donde normalmente realiza actividades de artes escénicas y brinda clases de cajón. Por su parte, Alexis Castañeda, el espacio en el que grabamos fue la fábrica de cajones que tiene ya hace veinte años, debido a que podía brindarnos mayor cantidad de información al momento de la exploración del tema y además mostrarnos toda la realización de la fabricación de un cajón. Por otro lado, la grabación con el cajonista Ricardo Huapaya fue realizada en un espacio nuestro ya que el personaje no podía recibirnos en su espacio laboral debido a la premura del tiempo. Se utilizó un espacio neutro con pared blanca para tratar de que no hubieran elementos distractores y poco relevantes para nuestro proyecto. Por último, la grabación con el sociólogo Javier Díaz-Albertini se realizó en su oficina, dentro de la Universidad de Lima. Se recurrió a este espacio debido al corto tiempo y disposición del profesor.

2.2 Propuesta técnica:

2.2.1 Plan de rodaje

Día 1:

\begin{tabular}{|l|l|l|l|l|l|l|}
\hline Personal & $\begin{array}{l}\text { Planos } \\
\text { referenciales }\end{array}$ & Fecha & Acción & Personaje & Equipos & Locación \\
\hline
\end{tabular}




\begin{tabular}{|c|c|c|c|c|c|c|}
\hline & $\begin{array}{l}\text { Planos detalle } \\
\text { los } \\
\text { instrumentos }\end{array}$ & $\begin{array}{c}2019 \\
\text { Hora: } \\
\text { 11:30 am a } \\
\text { 1:00 pm }\end{array}$ & & & \multirow{2}{*}{$\begin{array}{ll}\text { - } & \text { Cámara } \\
& \text { Canon T3 } \\
\text { - } & \text { Cámara } \\
& \text { Nikon } \\
\text { - } & \text { Pechero } \\
\text { - } & \text { Zoom } \\
\text { - } & \text { Kit de } 3 \\
& \text { paneles de } \\
& \text { luz led } \\
& \text { Yongnu } \\
\text { - } & \text { Tripode } \\
\end{array}$} & $\begin{array}{l}\text { Zárate. San Juan } \\
\text { Lurigancho., } \\
\text { Cercado de Lima }\end{array}$ \\
\hline $\begin{array}{l}\text { Jessica } \\
\text { Luisa } \\
\text { Fernanda }\end{array}$ & $\begin{array}{c}\text { Plano medio } \\
\text { Plano } \\
\text { americano } \\
\text { Planos detalle } \\
\text { de los } \\
\text { instrumento }\end{array}$ & $\begin{array}{c}\text { Martes } 17 \\
\text { de } \\
\text { Septiembre } \\
2019 \\
\text { Hora: } \\
\text { 3:00 pm a } \\
\text { 4:30 pm }\end{array}$ & Entrevista & $\begin{array}{l}\text { Ricardo de la } \\
\text { Peña del Carajo }\end{array}$ & & $\begin{array}{c}\text { Locación en } \\
\text { Miraflores } \\
\text { Av. } 28 \text { de Julio } \\
346 .\end{array}$ \\
\hline
\end{tabular}

\begin{tabular}{|c|c|c|c|c|c|c|}
\hline Personal & $\begin{array}{l}\text { Planos } \\
\text { referenciales }\end{array}$ & Fecha & Acción & Personaje & Equipos & Locación \\
\hline $\begin{array}{l}\text { Jessica } \\
\text { Luisa } \\
\text { Fernanda }\end{array}$ & $\begin{array}{c}\text { Plano medio } \\
\text { Plano } \\
\text { americano } \\
\text { Planos detalle }\end{array}$ & $\begin{array}{c}\text { Lunes } 14 \text { de } \\
\text { Octubre } \\
2019 \\
\text { Hora: } \\
\text { 7:30 am a } \\
\text { 8:30 am }\end{array}$ & Entrevista & $\begin{array}{l}\text { Sociólogo Javier } \\
\text { Díaz-Albertini }\end{array}$ & \multirow{2}{*}{$\begin{array}{ll}\text { - } & \text { Cámara } \\
& \text { Canon T3 } \\
\text { - } & \text { Cámara } \\
& \text { Nikon } \\
\text { - } & \text { Pechero } \\
\text { - } & \text { Grabadora } \\
& \text { reportera } \\
\text { - } & \text { Trípode }\end{array}$} & $\begin{array}{l}\text { Universidad de } \\
\text { Lima }\end{array}$ \\
\hline $\begin{array}{c}\text { Jessica } \\
\text { Luisa } \\
\text { Fernanda }\end{array}$ & $\begin{array}{l}\text { Plano general } \\
\text { Plano medio } \\
\text { Planos detalle }\end{array}$ & $\begin{array}{c}\text { Lunes } 14 \text { de } \\
\text { Octubre } \\
2019 \\
\text { Hora: } \\
\text { 11:00 am a } \\
12: 30 \text { pm }\end{array}$ & $\begin{array}{c}\text { Tomas de } \\
\text { apoyo }\end{array}$ & Francisco Vilela & & $\begin{array}{c}\text { Casa del } \\
\text { entrevistado } \\
\text { Francisco Vilela. } \\
\text { Villa el Salvador. }\end{array}$ \\
\hline
\end{tabular}

\section{Duración: 4 días}

Durante estos días se realizarán 4 entrevistas e imágenes de apoyo para el guión.

Para ello utilizaremos los siguientes equipos y personas: 
Equipo necesario para la grabación:

\begin{tabular}{|ll|}
\hline - & Cámara \\
\hline$\bullet$ & Lentes (2) Lente 18-55mm y Lente 16-35mm \\
\hline$\bullet$ & Trípode (2) \\
\hline$\bullet$ & Micrófonos \\
\hline$\bullet$ & Zoom (1) \\
\hline$\bullet$ & Pecheros (1) \\
\hline$\bullet$ & Kit de 3 paneles de luz led Yongnuo de 600 leds a colores \\
\hline
\end{tabular}

Personas necesarias para apoyo:

1. Productor

2. Camarógrafo

3. Sonidista

4. 1 Asistente

2.2.2 Plan de producción de necesidades y gastos

\begin{tabular}{|l|r|r|r|}
\hline \multicolumn{3}{|c|}{ PRESUPUESTO DOCUMENTAL 14/09-17/09 } & \multicolumn{1}{|c|}{ MONTO } \\
\hline EQUIPO DE RODAJE, ACCESORIOS Y MATERIALES & & & \\
\hline Cámaras Canon EOS 5D Mark IV & 2 & 3 & S/.1.800,00 \\
\hline Ópticas Canon EF 24-70mm f/4L IS USM - Canon 50mm f1.8 & 2 & 3 & S/.450,00 \\
\hline Luces Kit luces led YN600 RGB & 3 & 3 & S/.540,00 \\
\hline Sonido Grabadora de audio Zoom H6 & 1 & 3 & S/.300,00 \\
\hline LOGísTICA & & & \\
\hline Transporte & 1 & 3 & $S / .110,00$ \\
\hline Seguridad & 1 & 3 & $S / .300,00$ \\
\hline Postproducción & 1 & 2 & S/.1.000,00 \\
\hline Alimentación/Catering & 4 & 3 & S/.150,00 \\
\hline TOTAL & & & S/.4.650,00 \\
\hline
\end{tabular}




\section{SUSTENTACIÓN}

El presente documental se basa en plasmar el cajón como símbolo peruano de identidad nacional, a través de conversaciones con personajes que han incursionado toda su vida con este instrumento de percusión. Se presentarán testimonios de 4 personajes que nos contarán cómo este instrumento influyó en su vida, qué aporte tuvo en su vida artística y de qué manera se identifican con él como peruanos, también se incluirá la opinión de un sociólogo, sobre cómo el cajón es un símbolo valioso para nuestra identidad nacional.

¿Por qué elegimos como eje temático al cajón peruano para ahondar en el tema de identidad nacional? Consideramos que este instrumento es importante, pues además de ser patrimonio cultural de nuestro país, tiene una gran carga histórica, debido a que desde los procesos de migración en la época de la colonización, se dieron grandes cambios culturales dentro de la música y dentro de la sociedad misma.

El cajón peruano surgió básicamente de una necesidad expresiva de un tipo de población subalterna que soportó la esclavitud y las prohibiciones que no permitían que utilizaran sus propios instrumentos. A pesar de la opresión lograron que éste instrumento de pronto adquiera relevancia de manera más intensa dentro los principales géneros musicales del Perú.

Sabemos que es un momento muy importante llegar al Bicentenario para todas aquellas comunidades que han vivido una relación de dependencia colonial y que han podido desligarse de ello y mantenerse independientes durante un siglo más.

Finalmente, según la investigación realizada y de acuerdo a las opiniones de los cajonistas y expertos, podemos concluir que mantener vigente nuestra cultura a través de las distintas formas como la música, y entre generaciones es hacer un trabajo de resistencia para que nuestra identidad nacional se preserve en el tiempo y nuestros elementos culturales sean apreciados por los peruanos y por el mundo también. 


\section{RECOMENDACIONES}

- Proponemos plantear más días de grabación que incluyan demostraciones en conjunto de aprendices y estudiantes de cajón peruano.

- Se propone incluir tomas de apoyo de eventos exclusivos de percusión en escenarios como por ejemplo el evento Afro Perú en la Noche de Barranco y entrevistar a la audiencia para enriquecer el trabajo en cuanto a opiniones sobre el instrumento y cómo los lleva a identificarse como peruano dentro de una comunidad.

- Para una siguiente etapa del proyecto se sugiere entrevistar a un experto internacional para mayor investigación sobre cómo llegó a internacionalizarse el cajón.

- Se sugiere entrevistar a un historiador peruano con conocimientos de etnomusicología para profundizar en el tema de los inicios de el cajón, cuales fueron las influencias precisas y tener mayor conocimiento de las fechas en que se formó el sentimiento de pertenencia de dicho instrumento en el país.

- Se sugiere que para incrementar el poder de las historias, se utilice la grabación de foleys o efectos especiales del momento en que se construye un cajón peruano, con el objetivo de generar mayor expectativa y llegar a la audiencia mediante las sensaciones que genera escuchar dichos sonidos.

- Se sugiere ahondar más en la historia de 2 de los personajes para dar una construcción más amplia sobre su identidad como peruanos. 


\section{REFERENCIAS}

1. Milla Vidal, C., (2003), Construyendo la Identidad Peruana.

2. Madrid, A., Arrivillaga, A., Asturias A.,Ruiz Rodríguez, C., Spencer, C.,F. Díaz, C, Sanchez, W. (2010) A tres bandas Mestizaje, sincretismo e hibridación en el espacio sonoro iberoamericano.

3. Grebe,M. (s.f) Objeto, métodos y técnicas Etnomusicología: algunos de investigación en problemas básicos.

4. Bernabé Villodre,M. (2012) Pluriculturalidad, multiculturalidad e interculturalidad, conocimientos necesarios para la labor docente. Revista Educativa Hekademos, Universidad de Valencia.

5. Molano L, O. (2007) Identidad Cultural, un concepto que evoluciona. Revista Opera año/vol Nº 007 Universidad Externado de Colombia.

6. Guerrero Garcia, M. (2014) Del Cajón Peruano al Cajón Flamenco. Revista digital para profesionales de la enseñanza N²9 Federación de Enseñanza de CC.OO. de Andalucía.

7. Argibay, M. (2003) Conceptos básicos de multiculturalidad. Hegoa, www.bantaba.ehu.es Calfio Montalvo, M. et Velasco, L. F. 2005. Mujeres indígenas en América Latina: Brechas de género o de etnia, Seminario CEPAL, Santiago de Chile.

8. Martínez Valcárcel, N. (S.f) El Patrimonio Cultural: Valor Y Uso Educativo Que Se Hace En El Bachillerato De La Comunidad Autónoma De Murcia.

9. Hood, Mantle, (1957) "Training and Research Methods in Ethnomusicology". Ethnomusicology Newsletter.

10. Cairati, E. (2011). Afro Perú: Tras las huellas de la negritud en el Perú. Otras Modernidades 6(11): 121-138.

11. Real Academia Española. (2014). Diccionario de la lengua española (23. ${ }^{\mathrm{a}}$ ed.).

\section{ANEXOS}


1. Escaleta

\section{ESC. 1 - 3 LOCACIONES}

Observamos como Francisco, Juan Manuel y Ricardo tocan el cajón, luego aparece el título.

\section{ESC. 2 - INT. SALA DE FRANCISCO. DÍA}

Francisco nos cuenta qué significa el cajón para él y cómo aprendió a tocarlo.

\section{ESC. 3: INT. SALA DE JUAN MANUEL. DÍA}

Juan Manuel nos cuenta lo que significa el cajón para él.

\section{ESC. 4: INT. SALA DE FRANCISCO. DÍA}

Francisco nos sigue contando qué es el cajón para él.

ESC. 5: INT. SALÓN DE A TEMPO. DÍA

Alexis nos dice qué es el cajón.

\section{ESC. 6: INT. OFICINA DE JAVIER. DÍA}

Nos comenta en qué géneros se puede usar un cajón

\section{ESC. 7: INT. LOCACIÓN MIRAFLORES. DÍA}

Ricardo nos cuenta que en qué géneros musicales se usa el cajón.

ESC. 8: INT. SALÓN DE A TEMPO. DÍA

Alexis nos sigue explicando que es el cajón y sus inicios.

ESC. 9: INT. SALA DE JUAN MANUEL. DÍA

Juan Manuel nos cuenta cómo se inició el cajón.

\section{ESC. 10: INT. OFICINA DE JAVIER. DÍA}

Javier nos dice que el cajón es un elemento de la cultura afroperuana

\section{ESC. 11: INT. SALA DE FRANCISCO. DÍA}

Francisco nos cuenta cómo el cajón empezó siendo un medio de comunicación entre los esclavos.

\section{ESC. 12: INT. SALÓN DE A TEMPO. DÍA}

Alexis nos explica cómo nació el cajón.

\section{ESC. 13: INT. SALA DE JUAN MANUEL. DÍA}

Juan Manuel nos cuenta cómo el cajón nació por la opresión de los pueblos oprimidos.

ESC. 14: INT. SALA DE FRANCISCO. DÍA

Francisco nos muestra cómo se comunicaban a través del cajón en la época de la esclavitud.

ESC. 15: INT. SALA JUAN MANUEL. DÍA 
Juan Manuel nos sigue contando en dónde nació el cajón.

ESC. 16: INT. OFICINA DE JAVIER. DÍA

Javier nos menciona a qué tipo de música está asociado el cajón

ESC. 17: INT. SALÓN A TEMPO. DÍA

Alexis nos cuenta las características relevantes de un cajón.

ESC. 18: INT. SALA FRANCISCO. DÍA

Francisco nos cuenta qué siente respecto al cajón.

ESC. 19: INT. SALA JUAN MANUEL. DÍA

Juan Manuel nos cuenta qué sentimientos transmite el cajón a los demás.

ESC. 20: INT. SALA FRANCISCO. DÍA

Francisco recalca que debemos sentirnos orgullosos del cajón.

\section{ESC. 21: INT. LOCACIÓN MIRAFLORES. DÍA}

Ricardo nos cuenta qué sentimientos transmite el cajón a los peruanos.

\section{ESC. 22: INT. SALA JUAN MANUEL. DÍA}

Juan Manuel nos habla del valor actual que tiene el cajón.

ESC. 23: INT. SALA FRANCISCO. DÍA

Francisco resaltando la importancia del cajón

ESC, 24: INT. SALA JUAN MANUEL. DÍA

Juan Manuel nos cuenta cómo el cajón nos identifica como peruanos.

ESC. 25: INT. 3 LOCACIONES. DÍA

Observamos a Juan Manuel, Ricardo y Francisco tocar cajón, 
2. Entrevista a creativo con conocimientos de música peruana:

\section{GianCarlo Mantinieri}

Estratega creativo

Fusion Comunicaciones — Lima, Perú

\section{Puntos importantes de reflexión que recomendó para la investigación:}

1. Toda fusión viene y genera riqueza.

2. Todos somos el Perú, pero no todo el Perú está dentro de nosotros.

3. Somos un país que no tiene una, sino todas las sangres, hacer uso de lo que es la multiculturalidad e interculturalidad.

4. Expertos importantes en la historia del cajón para investigar: Valleumbroso, Hermanos Santa Cruz de Breña, Marco Aurelio Denegri, Nicomé de Santa Cruz, Victoria Santa Cruz y Miki Gonzales Valleumbroso.

5. Es importante indagar en las diferencias del cajón peruano y los cajones que se utilizan en otras partes del mundo.

6. Unión pueblos sometidos y castigados por el orden imperante como el negro peruano, cultura andinas y amazónicas que fueron relegadas y oprimidas encontraron en la música una expresión para formar el país de todas las sangres que somos nosotros.

7. Cómo el cajón viajó a través del tiempo, cómo enriqueció a la música criolla y cómo la música criolla también a otros estilos musicales.

8. Cómo la música sirve como expresión del alma para el peruano, cómo forma la identidad.

9. Cómo la música ha servido para que muchos pueblos soportan la esclavitud, la opresión.

\section{Recomendaciones para lo audiovisual:}

1. Maestro cajonero lijando/pulir madera cajón, terminando de armar un cajón.

2. Usar en el documental lo obvio que se está viendo, pero como excusa para contar una historia mucho más rica.

3. Buscar entrevistar a alguien que fabrique cajones, con experiencia como luthier 
4. Utilizar a la madera como componente importante.

5. Hacer uso de voz en off de entrevistados. Que cuenten algo propio pero que lo importante sea lo que hay detrás sobre el cajón.

6. Utilizar el cajón peruano como excusa para contar parte de la historia del Perú

7. Hacer uso de la idea de que el cajón es una ventana que se ha abierto para que el mundo pueda darse cuenta de qué otras expresiones pueden llegar al corazón del país que llamamos Perú.

8. Reconocer que somos un país, resultado de unas civilizaciones tan antiguas y ricas.

9. Manejar entrevistados en espacios propios para enriquecer el enfoque, hacerlos utilizar su propio instrumento también. 